\title{
The influence of sample preparation and incubation sequence on in situ dry matter degradability of fresh herbage in non-lactating dairy cows
}

\author{
JA Huntington, DI Givens \\ Feed Evaluation Unit, ADAS Dairy Research Centre, Drayton, Alcester Road, \\ Stratford-upon-Avon CV37 9RQ, UK
}

Recent ring tests and reviews have highlighted the need for improved standardisation of the in situ procedure. The aim of this experiment was to determine the effect of sample preparation and incubation sequence on dry matter (DM) degradability of grass from mono-filamentous polyester bags ( $43 \mu \mathrm{m}$ pore size).

The experiment was designed as a factorial plus control with two periods to provide sufficient replication for statistical appraisal. Three mature rumen cannulated Friesian cows fed a silage, barley diet (80:20; DM basis) were used. Bags were incubated simultaneously in both a forwards (0-72 h) and reverse $(72-0 \mathrm{~h})$ order with one bag for each treatment at each time per sequence. Preparation methods were fresh or frozen grass which were subsequently oven dried at $60^{\circ} \mathrm{C}$ or $100^{\circ} \mathrm{C}$, microwave dried or not dried. A grass sample was freeze dried to provide the control treatment. All samples were homogenised prior to preparation but were not milled following treatment.

Freeze dried grass was found to have the highest average DM losses $(P<0.001)$ (freeze dried and all other treatments means were $56.7 \%$ and $53.7 \%$ respectively). Freeze dried grass was also noted to have a different degradability profile to all other drying treatments $(P<0.001)$. The effect of freezing grass prior to drying was dependent on the drying procedure $(P<0.001)$. Frozen grass not dried was found to have a higher average DM degradability $(55.6 \%)$ than the equivalent not frozen sample $(53.6 \%)$. However, the effect of freezing diminished with increased drying temperature. Microwave dried grass was found to have the same average DM degradability as that of oven dried at $100^{\circ} \mathrm{C}(52.6 \%)$. A significant sequence $x$ time interaction was observed in the raw data, however, the effect of incubation sequence on fitted curve parameters and calculated effective degradability determinations were not found to be significant $(P>0.05)$. The table shows the effective degradability measurements ( $8 \% \mathrm{~h}^{-1}$ rumen outflow) for each treatment. The interaction between sequence, freezing and treatment was not found to be significant $(P=0.07)$. However, the table shows the tendency for freezing to increase effective degradability when the sample has not been exposed to high temperatures and for in situ bags incubated in reverse order to have lower effective degradability values.

It was concluded that DM degradability was affected by sequence and that freezing tends to increase the degradability of grass although subsequent heating may counteract the positive effect of freezing. Since there was no confounding effect of heating, freeze dried grass was assumed to exhibit the maximum affect of freezing on DM losses.

Drying treatment

sequence treatment

$\begin{array}{llll}\text { Forwards } & \text { Not frozen } & 43.59 & 44.27 \\ & \text { Frozen -20 } \mathrm{C} & 45.62 & 45.39 \\ & \text { Freeze dried } & & \\ \text { Reverse } & \text { Not frozen } & 42.90 & 42.76 \\ & \text { Frozen }-20^{\circ} \mathrm{C} & 44.85 & 43.50 \\ & \text { Freeze dried } & & \end{array}$

Oven $100^{\circ} \mathrm{C} \quad$ Microwave Freeze dried $42.59 \quad 42.90$ $41.72 \quad 41.71$

$40.79 \quad 40.36$

$40.94 \quad 41.46$

SED $=1.05 ;$ Treatment $\mathrm{df}=3$, Residual $\mathrm{df}=80$ 